\title{
Covid-19: US gives emergency approval to hydroxychloroquine despite lack of evidence
}

\author{
Jeanne Lenzer
}

New York

The US Food and Drug Administration has authorized clinicians to prescribe chloroquine and hydroxychloroquine for patients admitted to hospital with covid-19, despite warnings from scientific advisers that no randomized controlled trial has been conducted to support the drugs' safety and efficacy in this population.

In the emergency use authorization issued on $28 \mathrm{March},{ }^{1}$ the agency acknowledged that the approval was based on "limited in-vitro and anecdotal clinical data."

The FDA action followed President Trump's statements at a press conference last week that hydroxychloroquine showed "tremendous promise" for patients with covid-19, adding, "I think it's going to be great."

Trump cited a controversial French study of 20 patients published the previous day. Anthony Fauci, head of the National Institute for Allergies and Infectious Diseases at the National Institutes of Health, corrected Trump's comments, saying that they were based on anecdotes and not a controlled clinical trial. ${ }^{3}$

\section{The study}

The French study cited by Trump was led by Didier Raoult and evaluated 26 patients treated with hydroxychloroquine and 16 control patients, all of whom had tested positive for the virus at baseline. ${ }^{4}$ After six days of receiving $600 \mathrm{mg}$ of hydroxychloroquine a day, $70 \%$ of the hydroxychloroquine treated patients tested negative for the virus, compared with $12.5 \%$ in the control group $(\mathrm{P}=0.001)$, while all of those who had received hydroxychloroquine plus azithromycin (six patients) cleared the virus by this time.

Although Raoult reported the results as positive, he excluded from the analysis six patients in the hydroxychloroquine arm because they had not remained in the study for six days. The reasons for non-completion were that one patient died, three were transferred to the intensive care unit (ICU), and two withdrew. None of the 16 patients in the control group died, withdrew, or needed care in an ICU. Raoult announced that the study was of "great importance," since it showed that "hydroxychloroquine is efficient in clearing viral nasopharyngeal carriage of SARS-CoV-2."

The patient who died was polymerase chain reaction (PCR) negative for coronavirus at the time of his death.

An analysis by the French journal Prescrire International found that, "amongst the 18 patients for whom the date of onset of symptoms is known, the median time before non-detection of the virus was 7.5 days, with a wide confidence interval. In the absence of a control group selected according to a similar protocol and followed in the same conditions, it is not known whether this time is shorter than without hydroxychloroquine, or not."

Eight days after his initial study, Raoult posted the results of an uncontrolled observational study of 80 patients. In that study one patient died and one remained in the ICU at the time of the report, putting the case fatality rate at $1.3 \%$ or $2.5 \%$, depending on the outcome of the ICU patient. This compares with case fatality rates in Germany and the US of $0.9 \%$ and $1.8 \%$, respectively.

Raoult did not respond to requests for an interview by The BMJ.

\section{Increased prescribing}

Jerome R Hoffman, epidemiologist and emeritus professor of medicine at the University of California Los Angeles, told The $B M J$ that caution was needed because many treatments that initially seemed "promising" later proved to be harmful.

He said that FDA approval was likely to lead to increased prescribing of an unproven drug with well known adverse neurological and cardiac effects, which could lead to another problem-difficulty in completing clinical trials quickly and efficiently.

Hoffman said that studies showed that, once a drug was in widespread use, patients were reticent to be randomly assigned a drug, since they were convinced that the drug must be effective. " "It would seem prudent," he said, for the government to "explicitly discourage off-label use of experimental treatments, such as hydroxychloroquine for covid-19, until clinical trial data strongly point to a true benefit."

Hinton DM. Food and Drug Administration. FDA Emergency use authorization (EUA) o chloroquine and hydroxychloroquine. $28 \mathrm{Mar} 2020$. https://www.fda.gov/media/136534/ download.

2 Mahase E. Covid-19: what treatments are being investigated?BMJ 2020;368:m1252. 10.1136/bmj.m1252 32217607

3 Seley-Radtke K. Could chloroquine treat coronavirus? Sci Am 2020. https://www. scientificamerican.com/article/could-chloroquine-treat-coronavirus/.

4 Gautret P, Lagier J-C, Parola P, etal . Hydroxychloroquine and azithromycin as a treatment of COVID-19: results of an open-label non-randomized clinical trial. Int $J$ Antimicrob Agents 2020;105949. https://www.sciencedirect.com/science/article/pii/S0924857920300996. 10.1016/j.jiantimicag.2020.105949 32205204

5 Covid-19 and drug trials: what to make of the initial results? Prescrire Int 2020 Mar 23. https://english.prescrire.org/en/81/168/58599/0/NewsDetails.aspx.

6 Boles M, Getchell WS, Feldman G, McBride R, Hart RG. Primary prevention studies and the healthy elderly: evaluating barriers to recruitment. J Community Health 2000;25:279-92. 10.1023/A:1005153909429 10941692 
